\title{
Involving Patients with E-health: The Dialogic Dynamics of Information Filtration Work
}

\author{
Karen Dam Nielsen
}

\begin{abstract}
With e-health technologies, patients are invited as co-producers of data and information. The invitation sparks new expectations, yet often results in disappointments. With persistent ambitions to involve patients by means of e-health, it seems crucial to gain a better understanding of the nature, sources and workings of the expectations that come with being invited. I analyse the use of an e-health system for ICD-patients, focusing on how patients sought to serve as information providers. Continuing STS-research on invisible work in technology use, I show how using the system involved complex work of filtering information. I argue that this 'filtration work' was inherently dialogic, that is, characterized by receiver-orientation and the anticipation of response and guided by different communicative projects. For the patients, filtration work thus, first of all, required certain skills and knowledge about the infrastructure of care. Secondly, it entailed the expectation that the systemfor better or for worse-would facilitate not just information sharing but open up a dialogue, which glaringly contrasted with the clinicians' expectations of being able to better manage dialogue. I suggest that understanding the dialogic dynamics and 'overflows' of information filtration work can help unpack the challenges of facilitating (patient) participation with e-health and other filtration devices.
\end{abstract}

Keywords: e-health, patient participation, information filtration work, dialogue

\section{Introduction}

The basic storyline of the following anecdote may sound very familiar to readers acquainted with the field of e-health and telemedicine:

A group of researchers and clinicians set out to develop an ICT tool to involve chronic heart patients in their own treatment. Their approach is exploratory and highly usercentred. Through careful tinkering with prototypes in home and clinic, the contours are drawn for a system that will support the work of both patients and clinicians by enabling patients to provide health related information. But already in the pampering environment of pilot implementation, use practices prove difficult to establish and the expectations of users and designers alike seem impossible to fulfil. Clinicians lose interest, patients are disappointed, and in the end everyone involved seemingly agrees 
that this may have been a valuable learning experience, but not exactly a technological home-run in the quest for doing chronic care smarter by involving patients. "I'm afraid that this project will end up exactly as all the others. The doctor doesn't bother to read it, hasn't got the time. And then you spend millions on a system which won't work in the long run", as one patient evaluates.

Involving patients by means of $e$-health ${ }^{l}$ is a persistent ambition in healthcare (Berg, 2002; Felt et al., 2009; Danholt et al., 2013). Often framed as providing win-win tools, e-health is associated with the hope that involving patients in their own treatment will improve both the quality and efficiency of care (Archer et al., 2011; Wagner et al., 2010). But realizing the ambitions seems difficult. Pilots come and go and efficiency claims remain largely unsubstantiated (e.g. Miller, 2007; Tenforde et al., 2011). The lack of evidence for e-health efficacy may partly be due to the methodological difficulties of evaluating technology outside controllable environments (Pols, 2012). But besides being difficult to measure, the winwin situation may also simply be hard to achieve. As the example of user evaluations above indicate, a central problem is that people-patients and clinicians-have to do a lot of work to make the technologies work. STS and CSCW scholars have substantiated this insight repeatedly (Mort et al., 2003; Nicolini, 2006; Oudshoorn, 2008, among others). Moreover, for people to put in the work, it must be worthwhile. So when patients are invited as participants what follows are certain expectationsexpectations that are often not met and the invitation results in disappointment.

This article addresses this well-known schism by taking a closer look at the nature and sources of the expectations that follow when patients are invited to provide clinicians with information in new ways. What kind of work does this require? What expectations are entailed? And how come expectations are so often not met despite the careful efforts of designers to create tools capable of aligning different user needs? These questions are explored through the case of an e-health system for ICD-patients and the clinicians involved in their care, 'P-Record'2, introduced anecdotally above. An ICD is an advanced pacemaker that monitors the heart rhythm and, in case of arrhythmias, treats these by electrical impulses. The care for ICDpatients is divided between 1 ) a specialized clinic (device clinic) responsible for the ICD-device and remote monitoring and 2) the local hospitals' outpatient clinics (heart clinics) responsible for treating the patients' underlying heart condition. P-Record was designed as an add-on solution to this already technologically dense and distributed care scheme and aimed at improving coordination, communication and patient participation. This overall ambition was translated into a focus on facilitating the flow of appropriate and timely information between home and clinic by enabling patients to provide information. As such, the system shares with many other e-health technologies the basic script of serving as both a standardization and customization device. That is, the system was intended as a sort of filter that allows information to travel from home to clinic in a structured manner that fits clinical standards while at the same time opening up for an increased involvement of the individual patient. The tension between standardization and customization has been pointed out as a characteristic of the contemporary evidence-based healthcare paradigm at once patient-centred and rational (May et al., 2006; Storni \& Bannon, 2012; Moreira, 2011). E-health technologies may, as illustrated by P-Record, emphasize this tension by inviting patients to a kind 
of filtered participation. To understand the schism in e-health-the promise and expectations of patient involvement and the recurrent, subsequent disappointmentswe might therefore zoom in on what this filtered participation means in practice. How is it performed, who can join, and what does it imply for patients and professionals?

The article focuses on the work that users, and patients in particular, undertook to make P-Record work as a filter. It thereby continues in the line of a classic body of literature that stresses and unpacks the hidden work of technology use (e.g. Suchman, 1995; Star \& Strauss, 1999; Heath et al., 2000). However, the article also deploys a more communicatively oriented approach to the patients' filtration work by understanding it as a deeply interactional endeavour that involves specific dynamics and expectations ${ }^{3}$. Inspired by dialogism (Bakhtin, 1981; Linell, 2001), the article argues that providing information constitutes an intricate communicative work of assessing relevance and imagining (interactive) outcomes that in turn entails expectations of response. In other words, filtration work is a dialogically oriented work that involves the opening of a conversation and thus communicative and interpersonal dynamics that counter with and challenge the vision of scripting a structured, standardized information sharing practice, as well as individualizing ideas of e-health as facilitating self-care.

The article is structured as follows. First, I draw up the framework for the analysis by discussing P-Record's script as an information filter and, subsequently, outlining the article's core conceptualization: 'filtration as dialogic work'. After describing the applied methods, I turn to the analysis in which I unfold patients' and professionals' use and valuations of P-Record, showing the dialogic dynamics and derived implications involved in making P-Record work as a filter. In conclusion, I discuss the implications of the findings for e-health as well as the wider utility of the applied concepts.

\section{Filtering Information Between Home and Clinic}

While P-Record was designed to support the flow of information both between different clinics and between home and clinic, I focus on the latter script (Akrich, 1992) and the associated practices. I propose to describe this script in terms of an information filter; that is, a device that allows certain information to sift through and other information to be left out ${ }^{4}$. In information science, the notion of filtration is central, typically referring to a method for the delivery of relevant information as one strategy among others for dealing with information overload-filtration being the process of "leaving some types of information unprocessed, according to some scheme of priorities" (Savolainen, 2007: 612-paraphrasing Miller, 1962). Depending on the specific approach, filtration is understood as a cognitive and/ or social process that can be more or less supported or substituted by technical systems with the aim of "automatically directing the most valuable information to users [...] helping them to use their limited reading time most optimally" (Hanani et al., 2001: 203). Information filtration devices are manifold: spam filters and customized search engines are just some of the more mundane examples. These examples, however, also incarnate features and dynamics that may apply to other domains, as we might understand filters-or sievesbroadly as technologies of 'ontological transformation' (Kockelman, 2013). Indeed, while filters may be understood as "the simplest of interpreting agents", meaning is also "the quintessential form 
of sorting" (Kockelman, 2013: 37-39). As anthropological concepts, 'filters' and 'filtration' may thus describe how we order information and produce meaning in general.

The filtration terminology-in its more modest version-is also present in the field of e-health and telemedicine. A predominant narrative here is that filtering information is both necessitated and enabled by new technologies (Berner \& Moss, 2005; Eysenbach, 2008). That is, visions of e-health/telemedicine often involve a dual promise of increasing the production and accessibility of data and solving the subsequent need for filtering the vast amount of data made available in order to "provide meaningful quantities of health information to both patients and physicians" (Warren et al., 1999, my emphasis). Importantly, information filtration is recognized as an already crucial part of medical work where decisionmaking in a terrain of informational pluralism and uncertainty is a precondition. However, in the light of what has been called a 'patient information explosion' (Berner \& Moss, 2005), the call for formal filtration tools intensifies. Yet, the filters that are subsequently put in place with e-health/ telemedicine can also be perceived as being too efficient: they may cause vital clinical information to be left out (Lehoux et al., 2002), thus not solving but in some cases rather reinforcing the "struggle between information loss and information gain" (Mort et al., 2003: 292).

\section{P-Record as an Information Filter}

Although the term 'filter' is not explicitly used in the design of P-Record, the system materializes the co-creation of the problem and solution of obtaining and restricting information - of what to let in and leave out. First of all, the system was meant to support the automated production and filtration of data involved in remote monitoring. Every third month the data continuously collected by the ICD-device are transmitted through a communicator box in the patients' homes to the device clinic where they are analyzed by specially trained technicians (assisted by cardiologists). Data can also be acutely transmitted if either the patient or the ICD detects a cardiac or device event. Patients still visit the device clinic for semi-annual follow-ups, but before the introduction of remote monitoring, every ICD follow-up required a visit to the clinic. The core idea with P-Record was to provide clinicians with contextual information from the patients to be used in the interpretation of remotely transmitted data, that is, the patients' own accounts of general wellbeing, symptoms, and events. With the introduction of remote monitoring, this information-normally articulated during face-to-face encounters-has been 'filtered out'. Furthermore, automated data filters built into the monitoring system filter the raw data that are transmitted to the clinic, highlighting severity and character of recorded events. While this filtration makes the vast amount of data that is transmitted more manageable and potentially reduces the workload (Sinha et al., 2006), it also leaves the technicians with an interpretative uncertainty. In the face-to-face encounters, the technicians match the system's indications with contextual information, often leading the technician to reassess the automated filtration. In the absence of the patient, this reassessment is not possible. P-Record was an attempt to reintroduce the patient as information provider (or "diagnostic agent"), enabling yet again "interlinked processes of interpretation" (Andersen et al., 2011a: 6). Thus, with the aim of providing technicians with the contextual information otherwise 'filtered out' by the telemedical setup, P-Record can be said to be designed as an adjustment 
of the overall socio-technical information filtration in ICD-treatment.

Secondly, the system was designed to focus the face-to-face clinical encounters at both the device clinic and the heart clinic by providing a tool for preparation: the preparation form (figure 1). It consisted of four parts: general well-being, status since last consultation, symptoms, and questions for the upcoming encounter. The parts and their order were designed in a way that allowed for free text in the first part, then gradually narrowing down the patients' entries by asking the patients to write key words and arrange them after priority and, subsequently, to indicate symptoms by ticking off boxes linked to prefixed categories. The preparation form would thereby enable the clinicians to gain a quicker overview and focus the conversation with the patient-to "get to the point" (Andersen et al., 2011b)_and allow the patients to present their own narratives. This way, P-Record can be understood as in itself designed to both open and narrow the scope of information and to assist both clinicians and patients in their informal filtration of information before and during

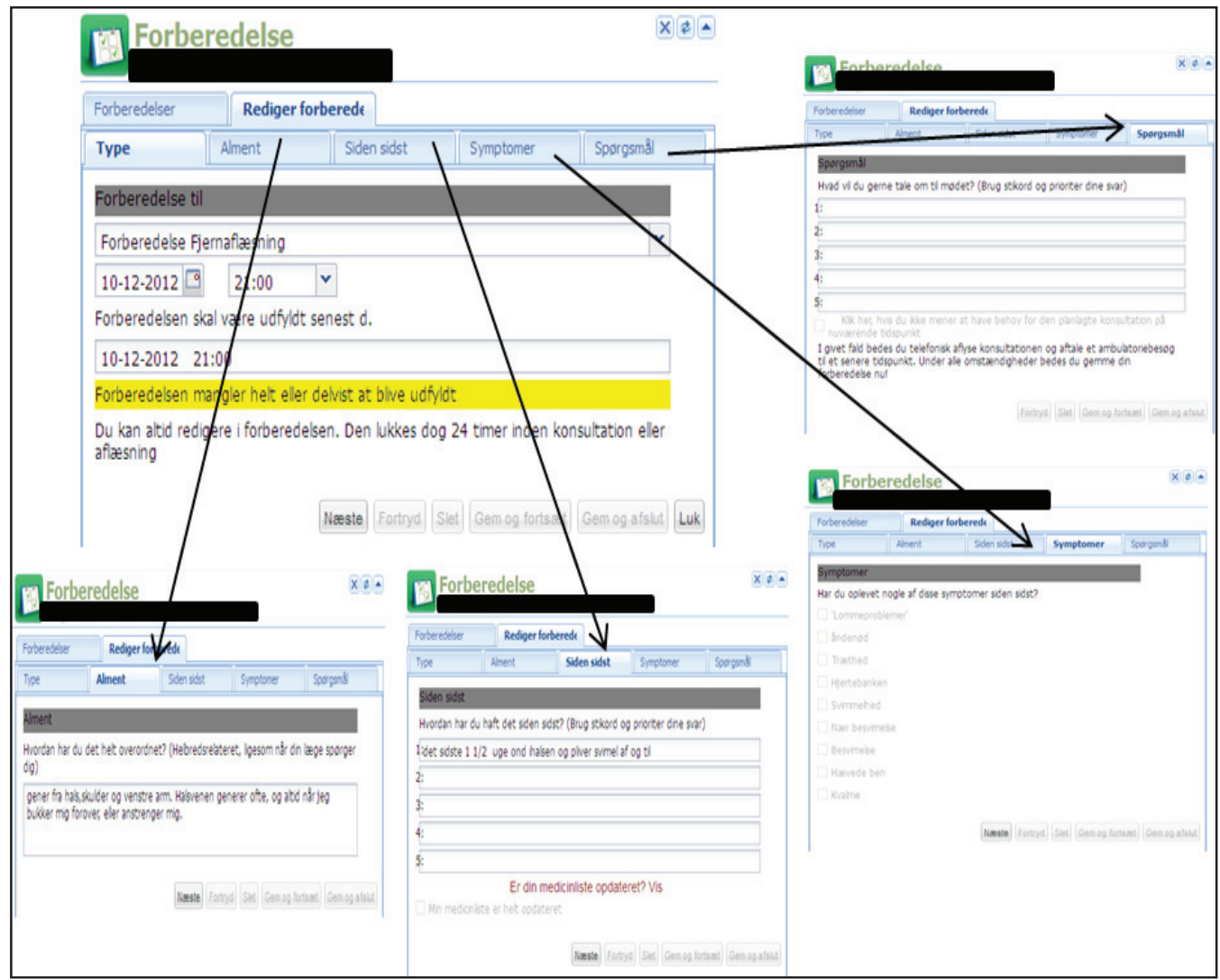

Figure 1. P-Record's preparation form. Consisting of four parts (besides the front page indicating the type of appointment): general well-being ('alment'), status ('siden sidst'), symptoms ('symptomer'), and questions ('spørgsmål') - in the example, partly filled out by patient-participants in the user-test (personal information concealed). 
the clinical encounter-a 'dual filtration script' that P-Record shares with other e-health systems (e.g. Basch et al., 2005).

'A filter' is a rather material figure, indicating a fixed structure that firmly defines what is let through. As such, a filter can be seen as a mechanical standardization device. In parts of the literature, it seems that e-health technologies are expected to work as filters 'by themselves' - as ensuring, through the materiality of their design, that just the right amount of information is enabled to travel from home to clinic. In the case of P-Record this expectation was also present among clinicians, as will be shown in the analysis. P-Record's script, however, also involves a promise of empowerment and customization by inviting patients to provide their own illness narrative and put individual concerns on the agenda. This invitation brings an ambiguity to the script, which in practice leads to the material filtration script being fundamentally challenged. As a filter, P-Record does not work on its own. Users have to act in certain ways to make it work: they have, I propose, to perform filtration work. Although phrased differently, this also resonates with how the designers originally envisioned P-Record as assisting, but not fully determining, "a process of formalization" of patient information (Andersen et al., 2010, adopting the concept from Berg, 1997) requiring that clinicians still perform a translation and that patients are trained in shaping information.

\section{Filtration as Communicative Work}

By directing analytical attention to the filtration work involved in the use of P-Record, I place the analysis within a practice-oriented framework. I approach filtration as a socio-technical and transformative process: a "subset of information and retrieval practices" (Leaver et al., 2012, my emphasis), which further can be understood as a specific kind of work, namely communicative work. In framing filtration as work, I draw on a valuable strand of STS-inspired research into telemedicine and e-health that has shown how informal or invisible work (Star \& Strauss, 1999) is required of both patients and professionals to make use and sense of new technologies (e.g. Mort et al., 2003; Oudshoorn, 2008; Piras \& Zanuttoi, 2010; Pols, 2012; Roberts et al., 2012). These studies have also given insights into the (re-)distribution of work that is entailed in using telemedicine (e.g. Oudshoorn, 2011). Work, in this line of studies, is used to describe users' practices of domesticating and tinkering with technologies (Langstrup, 2008; Pols \& Willems, 2011), producing knowledge (Mort et al., 2003), building relations and infrastructures (Oudshoorn, 2008), and coordinating and performing care (Langstrup et al., 2013).

I seek to further concretize the notion of work by proposing to look at the use of P-Record as communicative filtration work and subsequently unpack the inherently interactional practices involved in using ICT. I do this from a dialogic perspective. A common and basic feature of the multitude of approaches that label themselves 'dialogic' or 'dialogism' (e.g. Bakhtin, 1981, 1986; Linell, 2001; Phillips, 2011) is the ontoepistemological claim that human cognition and interaction are dialogic in nature. For the purpose of the following analysis, I focus on and adopt the most basic analytical figure of dialogism, namely the claim that every utterance is defined by other-orientation or addressivity (Bakhtin, 1986: 99), that is, inherently targeted towards a receiver. Producing an utterance thus involves the anticipation of its prospective interpretation and continuation-in short, "what is going to follow" (Linell, 2001: 100). This claim, I propose, resonates with and usefully sheds light on the use practices that went into 
making P-Record work as a filtration device. As Maurer (2013: 65) puts it, filtration-or sieving-“depends on a set of presumptions, a priori judgements or assessments of probabilities". That is, filtration rests on certain ontological assumptions. These are both transformative and continuously transformed by inference (Kockelman, 2013): we order our worlds based on our assumptions-including assumptions about others' assumptions-but our encounters with the world (and others) provide for recurrent reinterpretations and new assumptions. We adjust ourselves as filters, so to speak. I show how the specific filtration work that the users of P-Record performed was based on dialogic assumptions: it consisted of processes of imagining the receiver, the interactional situation, and the response-and shaping ones entries accordingly. Filtration work, I suggest, is thus a dialogic endeavour. And as a dialogic endeavour, filtration work entails certain dynamics and 'side-effects' making the use of P-Record a complex and, in some instances, quite problematic social practice.

The dialogic approach largely resonates with studies in ethnomethodology and, later, in CSCW that unpack the social dynamics of producing and sharing medical information. In his seminal study of practices of keeping medical records, Garfinkel (1967) precisely demonstrates how, in this case, doctors shape their entries based on anticipations of the future readers' interpretation and use and, recursively, read entries in recognition of their occasional rather than intrinsic meaning. In CSCW, this insight has been a key to understanding the challenges of digitalizing medical work. As demonstrated by for instance Heath \& Luff (1996) and later Berg \& Goorman (1999), digitalizing and, thereby, formalizing medical records clashes with the social and contextual nature of medical information. That is, ICT risks impeding rather than supporting the flexible, situational and receiver-oriented record keeping practices, which build on a shared, tacit organizational rationale rather than formal standards. When studying the use of ICTs that also include patients as information producers, I propose that a dialogic framework very precisely brings forth the challenges and implications of coordinating information filtration practices in the absence of a shared organizational rationale.

\section{Methods}

The article is based on ethnographic research conducted during a 3-month user test of P-Record. The user test involved 6 patients and 6 clinicians at the outpatient heart clinics of two Danish hospitals. During the user test, patients were to prepare for and participate in three kinds of clinical encounters using the IT-system: a remote follow-up of their ICD; an in-clinic ICD follow-up at the device clinic; and a consultation at the local hospital's heart clinic. These activities together constitute the existing distributed care scheme of ICDpatients. However, due to the timeframe of the user test, these activities were rescheduled to take place closer to each other in time than normally. Throughout the user test, I acted as facilitator and instructor. Patients were given instructions in their homes. All parts of the system were demonstrated at the initial visits, although with an emphasis on the more extensive functionalities (the preparation form and medication list) linking to upcoming appointments in the clinics. The visits also involved interviews with the patients. Likewise, the system was demonstrated to clinicians individually, however, in a briefer manner due to the limited time available in the clinics and the knowledge of the system that they had already gained through their participation in the design process. During 
the user test, I accompanied the patients at their visits to the clinics and had telephone and/or email contact with all patients on more occasions. By the end of the user test, all participants were interviewed about their experiences during the test.

By serving as both facilitator and ethnographer, I took on a highly interventionist approach. To turn the challenges of this approach into analytical resources, I treat the user test of P-Record as both the object of study and a heuristic device-a transformative filter, so to speakallowing me to gain understanding by disruptively bringing about more nuanced data (Hasu \& Miettinen, 2006) and engage with frictions (Zuiderent-Jerak \& Jensen, 2007). As part of the following analysis, I thus draw on the insights gained as I became a central knot in the infrastructure and interactions and, thereby, experienced first-hand the dialogic dynamics involved in the use of P-Record.

The analysis is structured as a gradual unfolding of these 'dialogic dynamics' by following the flow of interactions between patients and clinicians as they took place during the user test. In the first section, I show how patients made use and sense of the tool as a way to address clinicians. Then, I show how clinicians perceived and responded to the patients' entries. Finally, I turn to how patients perceived the clinicians' reactions. At the end of each section, I discuss how the (dialogic) use practices can be understood as filtration work.

\section{Writing to Someone}

The design of P-Record only vaguely indicated the identity of the receiver of patients' entries. However, a defining feature of how the patients used the system was that they addressed their writings to someone: either a specific receiver or a generalized receiver. Proceeding from this observation, I propose that the patients' use of the system was characterized by addressivity (Bakthin, 1986; Linell, 2001): their entries were directed towards a receiver with the anticipation of a response and shaped accordingly. That is, in deciding what to write, patients performed a dialogic assessment: they based their assessments of relevance on careful considerations about whom they were writing to; what the receivers might want; and what kind of responses to expect. This dialogically oriented process of shaping entries proved a complex interpretative task of descripting not only the system but also, and especially, the context of use-that is, the overall practices and infrastructures of care that make up the 'real environment' that P-Record only vaguely describes (Akrich, 1992).

\section{Knowing the Receiver}

During the user test, patients were to prepare for three different clinical encounters. The preparation form was, however, generic; there was no technical shaping of the patients' entries according to the different kinds of consultations. Instead, the patients took on the work of filtering information for the different consultations by trying to envision who would be at the other end and what information this person would want, also envisioning what actions could be taken. Therefore, the work of filling out the preparation form first of all became dependent on how clear the division of work between different clinics and professionals was to the patients. Some patients were well aware of the infrastructure, as the participant Anne (a health professional herself and long time ICD-patient) who even knew, in details, about the distribution of competencies among named clinicians in the same unit. When filling out the first part ('general well-being') of the preparation 
form for remote ICD follow-up, she stated: "is doing fairly well", despite being troubled by various symptoms on a daily basis. When I asked her about her choice of words, she said:

The problem is that is only our technicians [who read it], right. They can't... it is only about the technical side of the ICD, right. That is why I said to you on the phone: but who sees it? None of the doctors do. They [the technicians] can't go into all that, neither regarding my medicine or symptoms or how I have been feeling. (First interview with Anne)

Later, when preparing for the in-clinic ICD follow-up, she writes that she is experiencing nuisance in her right shoulder and neck caused by the device pressing on a vein. But she is in doubt about the relevance of raising this issue:

It doesn't help to talk to Mark about it. Then I would have had to get an appointment with... then we should have called in John [cardiologist]. But it wasn't that important, I think. [...] If it was a real system that was up and running then we would have to talk about it. But then I would probably have called them [...] because usually when you're at the clinic for a reading then it is not supposed to be a conversation with a doctor or a talk at all. (Final interview with Anne)

Anne here assesses the meaningfulness of raising the issue based on well-founded assumptions about the receiver, considering both if the receiver will be able to act on it and if the severity should spark her to try to address another potential receiver by other means. She thus pragmatically draws on her extensive knowledge about the division of work in the clinic. And in the end, her interpretation of the infrastructure of care seems to lead her to make a shift in perception from regarding the clinical encounter as the context of use to seeing the user test as the context or purpose in relation to which she assesses the relevance of her entry. As she explains when asked why she chose to raise the issue about the neck vein after all:

I think it was just as much because I had to write something [laughs] so that we would have something when we got there [to the first test consultation at the clinic]. (Final interview with Anne)

For other patients, the distributed care scheme and lack of a regular contact person among the clinicians caused greater uncertainty about who to address and, consequently, what would constitute relevant information. This was strikingly evident for the participant, Ben, who to some extent had given up on understanding the infrastructure. Therefore, when filling out the preparation forms for the three different appointments, he did not address a specific receiver but wrote with a collective, cross-institutional, and "typified" (Linell, 2001: 103) receiver in mind-'the doctors'although he had experienced this collective as highly fragmented:

Interviewer: And does it mean anything to you who will read it at the other end?

Ben: I almost don't care when it comes to the doctors. [The local hospital] and [the device clinic] each have their own opinions, that is for sure.

(Final interview with Ben)

Ben's way of using the system shows, in an intricate way, how the directedness towards a receiver is both inevitable and highly challenging. He may not be addressing a 
specific receiver but he nonetheless writes from an experience that it does matter which clinicians he is in contact with in terms of which interpretations and decisions will be made, that is, how his utterances will be filtered differently by different receivers. On the one hand, his lack of knowledge about the division of work between the different clinicians meant that relevance became hard to assess and he repeatedly consulted me for advice on what to write. Even at the end of the test period, when filling out the preparation for a visit at the heart clinic, he was still very insecure about what to write, although he could now draw on experiences of what had proved relevant-or irrelevantto other clinicians at previous encounters:

Ben: 'How have you been since the last time?' Well, what should I say? What should I write now? [...] I would like to have a day monitor put on, now that I'm working, to see the next 24 hours.

Interviewer: You could write that as a question, for instance 'Can I have a day blood pressure monitor put on?'

Ben: Yes, that's what it said here [in the preparation form] the last time I was at [the device clinic], but as she [the doctor] said, it was [the local hospital] who handled that case.

(Extra visit and instruction with Ben)

Provided with a new means of contact (P-Record), Ben also on his own initiative attempted to bridge what he experienced as a gap in the infrastructure causing him great anxiety. Requesting to have his blood pressure measured over the course of a working day-something he had discussed with his GP-in his preparation forms for his appointments at both the heart clinic and at the device clinic can be seen as a persistent attempt to make the issue a shared responsibility across institutional boundaries. And perhaps more distinctly, he used the system to navigate in the complex infrastructure by directly addressing $m e$ through the e-mail feature (e.g. with questions regarding appointments outside the context of the project and by forwarding referral letters asking me to help make sense of them), thus making me, at times, the primary and only specific receiver. Ben this way, like Anne, partly shifted his orientation from the clinicians as receivers and the clinical encounters as the context of use to the researcher and the research project-in his case, because the infrastructure remained incomprehensible to him.

\section{Anticipating the Answer}

Besides considering who the receivers might be and what they might want, the patients shaped their entries according to reflections on what response they might get and, more subtly, how they would be perceived as senders and how they wished to perceive themselves. For the participant, Carl, these considerations all come together when he is filling out the preparation form for the consultation at the heart clinic and together with me tries to establish what would be relevant to write. Carl takes into consideration the severity of certain health issues and relates it to his knowledge of the division of work between the cardiologist and his GP. He has had a cough recently but does not think that it is severe and is therefore content with already having discussed it with his GP- "it's nothing to start ranking up", he says. His assessment of what is relevant to write is further influenced by his overall experience of illness: how certain symptoms become part of 'the normal' and how he is coping with illness by insisting on a good general wellbeing: 
Interviewer: If what has characterized the situation the most is that you have felt short of breath, then you could write that.

Carl: Well, yes, but they know that because it has been like that for many years now. [...]

Interviewer: And then there is the option to write five things, but you don't have to write five things.

Carl: No, no, no, because I feel fine. But, well, there is just... when I bike or [walk] up the stairs then I pant a lot, right. That's the only thing. Because otherwise I feel all right. There's nothing the matter with me. (First visit and instruction with Carl)

Later, when filling out the preparation form himself before the consultation at the heart clinic, Carl first states that he "is doing fine" but when asked directly about symptoms, he ticks off almost all boxes: shortness of breath; dizziness; swollen legs; palpitation; and fatigue. On the last page of the online preparation form (questions for the consultation), he repeats "shortness of breath", "dizziness" and "swollen legs". He later explains that he would not normally take these things up as he has just conformed to them as conditions and only thought of them because P-Record provided the keywords. This way he acts according to the script of the system in the sense of being sparked to articulate symptoms that he would normally remain silent about - to adjust his usual filtration by letting more through. At the following visit, the cardiologist asks about the symptoms and touches upon lifestyle issues. However, Carl just comments and nods evasively and disinterested and afterwards states that he knows all this, they have talked about it before, but he prefers to continue his lifestyle and just enjoy whatever time he has left. He adds that he would not find the system meaningful outside the realm of a research project; he is happy with the existing care scheme to which he complies. For Carl, the very act of writing about symptoms conflicted with his choice not to focus on illness and, furthermore, sparked the articulation of lifestyle issues at the consultation that he regarded as pointless and merely tiresome to address repeatedly.

Carl's case thus points to a consideration that may be part of patients' filtration of information, namely the wish to minimize the focus on disease. Carl's way of assessing relevant information when shaping his entries mirrors his way of communicating with clinicians in general and can be described as a balancing act between providing the necessary information and keeping symptoms unarticulated-the goal of the balancing act being to cope with illness in a way that minimizes its overall impact in everyday life. He thus filters information with the prospective continuation of the dialogue in mindimaging not only who the receiver might be and want, but also considering what kind of conversation his entries will lead to and, subsequently, how this will (negatively) affect his overall coping with illness.

For other patients, imagining what their entries would entail played out as attempts to foresee more specifically what kind of answers they might get from the clinicians. Anne, who chose to raise the issue of a nuisance around her neck vein caused by her device, anticipated that she would not get a response since the issue would be outside the scope of the receiving technician's competences. She also expected that there simply would not be time to respond for the receiving clinicians in the device clinic since "they already have plenty of work with all that remote monitoring" and using P-Record would "take a lot more resources". Besides drawing on these assumptions about the conditions of work in the clinic, 
she furthermore based her anticipation of response on an assessment of severity; that is, if a certain issue would be considered topical and serious enough by the clinicians to be acted upon. In a circular way, she links her assessment of what the clinicians may regard as serious to the choice of media: using P-record to raise a certain issue may in itself indicate to clinicians that it is not something they need to respond to. As she says:

If I can be content with sending a message then it's not that serious, you know, then it's not something they have to act on here and now. Because if it was serious then I would get on the phone and call them or I would rush off [by ambulance]. (Final interview with Anne)

Finally, Anne takes into account that the issue may not be 'actionable' (Andersen et al., 2014) at all. That is, the answer she has been given so far is that nothing can be done about it. This adds to her anticipation that raising the issue of her neck vein will not spark an answer in the hoped-for-sensethat is, some kind of clinical action that will solve the problem-and thus not be worth the effort.

\section{Experimenting with Dialogue}

In her writings and deliberations, Anne is constantly torn between pragmatic expectations and a wish to experiment as a participant in a user test. Contrary to the script of the system as a means to 'open the scope of information' in relation to remote monitoring especially, Anne chooses to write more extensively to the inclinic follow-up. Imagining the interactive situation, she concludes that if she is to write something in P-Record it will make more sense for her to provide information when it can actually become the basis of a conversation:
I can't talk to them in connection with the preparation for [remote device control] so I wrote generally. [...] When I thought about, okay the third of December I am going there [to the clinic], then it was important to include other things, symptoms and so on. (Final interview with Anne)

For her, the potential lies in the hope that providing more information will lead to a richer (face-to-face) conversation. This goes for the patient, Louis, as well. At first glance, he seemed to do 'less' filtration work compared to the other patients who all wrote in a very concise manner. Louis wrote extensively in both the preparation form and in the logbook ${ }^{5}$ and, in the eyes of the clinicians, really "opened the floodgates" with entries like this:

I continue with dizziness and general
fatigue, which sometime gets really bad,
other days is okay. I have arrhythmias
many times a day, especially when I
rest. Haven't experienced it while I walk
or anything else. The legs are always
weak and of course with great differ-
ence in temperature. The right leg feels
numb sometimes. That may also be due
to the lack of vitamin D since I stopped
taking them in December. (Louis' log-
book, symptom note)

He did, however, still perform a selection of information, only, he regarded the system as a chance to open rather than narrow the scope and provide the information that he was afraid was missed in the existing care scheme. Like for other patients, the distributed and technologically dense character of ICD-care made Louis feel that no one saw the full picture of his condition and treatment and that crucial information was lost. In his case, the infrastructure was complicated by his participation in a clinical 
research project where he underwent additional in-clinic device follow-ups as well as various blood tests, measurements, and scans. Although he could be said to be under closer surveillance through the project, all the extra data produced only caused frustration and uncertainty since he experienced that they were neither shared with him nor with the clinicians responsible for his treatment. On this ground, Louis' extensive writings-together with his persistent suggestions to add a file-sharing feature for test results to the system-can be seen as his attempt to mend a severely flawed information infrastructure. Thus, he does undertake filtration work by trying to assess the value of the information he gives and, reversely, the risk of leaving out information. He writes from the hope of receiving better answers by providing more information but is at the same time rather pessimistic, worrying that the clinicians will tell him that they "don't want to hear that story anymore".

To Louis, the system provides, if not a promise of resolving his uncertainties, then a chance to make the clinicians take on responsibility and sort out his concerns. Like Anne, Louis chose to experiment, testing new possible questions and responses in the clinical encounter. They both raised more issues than they actually anticipated a response or reaction to and thus did not just interpret the context of use in light of existing practices, but also tried to push the receivers towards new practices by addressing them in new ways and with otherwise neglected issues.

\section{Addressivity as Filtration Work}

A main intention with P-Record can be described as to 'lure out information' in a strictly focused manner. The work of filtering information was to some extend built into the system with the structure of the preparation form aimed at gradually narrowing down and formalizing patients' narratives. However, most of the patients pre-empted the focusing questions by deeming most of what could be written as irrelevant and writing in a concise and brief style in all parts of the preparation form. Rather than being restricted in their writings by pre-set limitations of the system, they seemed to restrict themselves according to their assumptions about the receiver, interactive situation and possible outcome. The patients' writings (even the more extensive ones) were shaped through communicative work based on an understanding of P-Record as a tool for opening a dialogue rather than 'pure' information sharing. The information they provided was a product of receiver-oriented filtration work, instigated, partly supported, but far from 'automatically' performed, by the device.

\section{Receiving and Responding}

So how did the clinicians use and value the information given, and how did they respond? The clinicians' performance as receivers and responders can be understood as an enactment of their descriptions of P-Record as a filtration device, as well as their 'responsive attitudes' (Linell, 2001: 104).

\section{P-record as a Filter (and Receiver) in Itself?}

At the local hospital the cardiologists attempted to use the system to focus the face-to-face consultations and thus valuated the patients' entries accordingly. In some cases, they perceived the entries as containing surplus information but were satisfied with the way the system then allowed them to screen this out and "get to the point". In other cases, they perceived the patients' entries as a satisfying way of getting the information that they need but 
often have to work hard to obtain from some patients. One of the cardiologists summarized the value of the system as a means to both opening up and narrowing the scope this way:

You could use it both ways, really. To get the swarm of thoughts that occupies some patients under control, where it just pours out of them. And then with this guy [the patient Carl] it was more the case that if you ask [then he answers] 'it's going well' and [you say] 'okay, then we don't have anything else to talk about'. He would be the kind of guy who then comes home and the wife asks 'why didn't you ask about all these things' or where it pops into his own mind 'oh, maybe I should have asked about something'. (Final interview with Peter, cardiologist)

Two cases lie behind this statement. One of them is Carl, who, provided with keywords in the preparation form, articulated more symptoms than he normally would do at a face-to-face encounter. When evaluating the system later on, the cardiologist highlights Carl's case as an example of the potential value of the system as it allowed him to get information about symptoms that he would normally have a hard time getting Carl to talk about-a 'success' that the cardiologist also tries to share with Carl at the consultation:

Peter: Do you have anything else on your mind?

Carl: No, cause I feel fine.

Peter: Yes, but that's kind of funny because I can see that you write that you are feeling fine but then there was something about being short of breath and there was something about water in your legs.

Carl: Well, yeah...
Peter: But it's fine that you are doing well, but still, now we can adjust the details a bit, right.

Carl: Well, I just thought that I'm so used to being short of breath so you just cope, right.

(Transcript, Carl's visit to the local hospital)

The other case, initially referred to, is Louis, who wrote extensive entries in an attempt to ensure the articulation of crucial information and to push the clinicians to provide the answers and actions needed to reduce his anxieties. At the consultation, the cardiologist only took up a few of the issues that Louis had raised in the preparation form and later described Louis' entries as "very unstructured with these novel-like or diary-like entries that I can't live up to", also referring to them as "solemn phrases". Despite his critical attitude towards Louis' writing style, or exactly because of this, he thought the system proved useful in the situation by allowing him to "control the contact" by quickly screening the information given and avoid its articulation in the brief consultation, thereby perceiving P-Record as facilitating a win-win-situation:

He had kind of got it out. [...] Then it was like he knew that I knew a whole lot, which we then didn't have to sit and start all over on. So this way I actually think that the patient is allowed to get rid of it and I'm allowed to hear it without it taking up too much space. Then they get what they need and I get what I need. I need something more structured and concise. [...] If he should sit and present a bigger dramatic contribution in the consultation then it would come between us. (Final interview with Peter, cardiologist)

The cases illustrate how the cardiologists seemed to consider the system, at best, as 
a filter that allowed them the information they needed to respond to the patients' heart conditions and not their general concerns. They further seemed to perceive the system as an adequate receiver in itself: that patients would feel good just getting something off their chest by writing about it and that the clinicians then would not have to spend time on responding to (for them) irrelevant matters. The cardiologists thus regarded P-Record as a filtration device able to remedy existing problematic filtration practices and assist them in their own filtration work. As such, P-Record succeeded in the concrete cases, yet, it did so by also rendering the patients' filtration work 'functionally invisible' (Star \& Strauss, 1999) and thereby masking the dialogic imaginations-or expectations-entailed. However, the cardiologists did worry that, at worst, they "would actually be tested in if (they) had read and understood it all" by the patients, whereby the system would fail as a filter.

\section{Shifting Responsibility}

At the device clinic, the participating technician, Mark, differed from the cardiologists in his responsive attitude, being eager to provide an answer although this was no straightforward task. The system meant that some patients would raise concerns that seemed to exceed the kind of medical analysis and decision-making normally included in his job. This caused insecurity in relation to answering, as in the case of his remote follow-up of Anne where I accompany him:

Interviewer: What she has written in the preparation (form) - isn't that relevant for you?

Mark: Well, yes, but she's feeling all right... If she writes 'my legs are swollen' then I have to get a doctor and say 'look here, you have to write to this patient'.
Or if the patient writes 'I've had extra heart beats' or something like that, then it can be related to the arrhythmia. So in that sense it does matter to me, right. Interviewer: But is it then something you have to act on now when she writes about feeling a pain around her neck vein? [...] Is that something you would normally decide on?

Mark: No, because she has made a transmission (remote transfer of ICD data). Now, it's just that she writes... Well, I would write a message to her 'if the swelling and pain around the neck vein continues you should contact us'. That's what I would write. [...] Yeah... but... should we write something to her? (Transcript, remote follow-up of Anne's ICD in the device clinic with Mark)

However, by being able to write a message saying "call if the problem continues", Mark was also relieved from responsibility for further reaction, as he could pass this on to the patient. For Mark, passing on the responsibility for reaction became a way to 'filter' the patients' concerns one more time. This filtration both served to help him in his medical decision-making, based on the rationale 'if it is really important they will call' (as illustrated by Anne's case), and to save time:

Mark: You can communicate quickly [with P-Record]. Right now we have a problem with a patient who does not answer his phone. Then you spend a lot of time calling the patient again and again. If he had this system then we could have said "please just call us", right. [...] So you can say, it's up to the patients [who] also have certain obligations themselves. It's their disease; it's not ours. If they had this [P-Record] and something came up then they would have to go in and tell us if there has 
been anything. [...] But he hasn't contacted us, the guy from yesterday, so he can't be doing that bad.

(Final interview with Mark)

\section{Filtering to Manage the Dialogue}

As a filtration device, P-Record successfully assisted both the cardiologist and the technician in managing responsibility "in a field riddled with uncertainty" (JerakZuiderent, 2012: 738). For the cardiologists, P-Record lived up to their expectations as it supported them in their efforts to respond only to issues within their specialization. The cardiologists seemed to perceive P-Record as a more or less 'automatized' filtration device, not recognising the filtration work done by patients (and its implications) as a crucial part of making the system work (or not). On the contrary, the cardiologists evaluated the system in terms of how well it succeeded in filtering the patients' narratives, thereby supporting them in obtaining just the right amount of information to inform clinical decisionmaking and "control the interaction". As a filtration device, P-Record also proved a valuable tool in the work of the technician in his 'frontline', experimental attempts to sort urgency from non-urgency and restrict access to specialists - to "act while trying to know" (Jerak-Zuiderent, 2012: 742). In assisting him in filtering information, P-Record also became a means for filtering access to the clinic, as he could use the system to push the interactive initiative back to the patients and to another medium: the telephone. This way P-Record became an additional layer in the existing filtration of the contact between home and clinic, and although not an explicit design intention, the system then came to hold another common e-health script as an 'access filter' (e.g. Moreno-Ramirez et al., 2005).

\section{Continuation of the Dialogue}

In their evaluations of the clinicians' responses, the patients were torn between pragmatics and disappointment. I suggest that this links back to how their filtration work rested on addressivity and thus entailed drawing on previous experiences of what one can expect (or not) from certain clinicians and a basic expectation of response inherent to the opening of a dialogue.

\section{Realism, Hope and Disappointment}

Although presented with a system that seemed to promise an improvement of communication both ways, several patients indicated that they, for various reasons, did not really anticipate an answer after all, as illustrated earlier and especially clear in the case of Anne. Besides her awareness of the constant lack of time in the clinics and the limitations of the receiver's ability to act, she also recognised the issue of her neck vein as simply unsolvable. This realism led to rather low expectations in the concrete situation and she evaluated the answer she was given accordingly:

Interviewer: Then Mark wrote to you after the remote reading?

Anne: Yeah, he sent this [reads out loud from the screen]: 'Your transmission has been read, everything found okay. If swelling and soreness are persistent, please contact us'. But he can't do anything about it.

Interviewer: No. So what do think of an answer like this?

Anne: Then I say, well, they know and what are they going to do about it.

(Final interview with Anne)

Being realistic, in the sense of understanding and taking into account pre-existing realities, like the infrastructure, 
the qualifications and attitudes of specific clinicians, and medical circumstances, to some extent seemed to minimize disappointment. As I have shown, the patients who took these realities into account seemed better able to address the clinicians in a manner that the clinicians appreciated: they wrote in a concise manner and held what turned out to be a realistic vision of what outcome to expect. In contrast, Louis and Ben, both relatively new ICD-patients with little experience of the 'realities' and an urgent need for contact, wrote extensively and without a specific (named) receiver in mind hoping to spark a reaction from the collective of clinicians or 'push realities', but with little effect.

However, all patients did on some level expect an answer and expressed being discouraged by the (lack of) response given. As Anne states, despite her pragmatic attitude and awareness of the "realities":

I would like to use it [P-Record] but then I want some response to what I have written. If I ask some questions or have some problems in relation to my heart condition or my ICD then I want either time in the clinic or a response from them. That requires that the staff will do this seriously. (Final interview with Anne)

For some, the disappointment first of all seemed to be caused by the response not entailing the hoped-for action, as in the case of Ben, who in his preparation for his consultations at both the device clinic and the local hospital had asked for a 24hour blood pressure monitor and asked for advice regarding an over-the-counter drug. At the device clinic, the technician and accompanying cardiologist did not explicitly take up any of the issues and only gave a brief answer when Ben asked directly, saying that these were matters for the local hospital to handle. At the local hospital, the cardiologist did address Ben's request for a 24-hour blood pressure monitor but simply did not agree with it. He also browsed through Ben's medication list ${ }^{6}$, suggesting a few adjustments, but not addressing the issue of the over-the-counter drug that Ben had listed with a question mark. The fact that the action he requested was not taken and the issue of medication not explicitly addressed left Ben with a feeling that his preparations had been useless. For Ben, P-Record did not facilitate a more coherent dialogue across institutional borders, as he had hoped for, and it did not lead to the hoped-for action, thereby in sum not reducing his concern that no one was taking responsibility for his overall situation.

For others, disappointment seemed more about not feeling heard at all. Having written extensively in the preparation for his consultation at the local hospital, Louis was hugely disappointed with the verbal response he got from the cardiologist as expressed in his later imitation of how the cardiologist, only looking at the screen, quickly browsed through and, subsequently, disregarded the issues Louis had raised:

Maybe it is easier for the doctor himself to have this little system [...] then it is much easier for them to say, 'okay, blabla-bla-bla-bla'. [...] I looked forward to this consultation [but] it was more like an IT-consultation, as I call it. [...] I call it an IT-consultation when a doctor doesn't bother to listen and he just sits in front of you and says 'okay, so and so and so'. (Final interview with Louis)

Clearly, Louis did not support the cardiologist's appraisal of P-Record as allowing both patient and clinicians "to get what they want". To Louis, just "getting something off his chest" without subsequent articulation during the consultation was far from satisfying. 


\section{Filtering to Open Up (a Better) Dialogue}

Louis' and Ben's cases point to a central ambiguity related to the quest for answer entailed by their dialogic filtration work; namely, what actually constitutes an answer? The users' perceptions of this ranged from the idea held by the cardiologists that the shear reading of a patient's entries somehow makes up a response, or at least a satisfactory reception, to the request by some patients that concrete clinical actions should be taken in order for them to feel that their entries had sparked a true reaction. In between these two extremes was a blurred terrain of different kinds of verbal or written answers that seemed to constitute relatively satisfactory answers for patients with low expectations and for others were so insufficient that they felt no response had really been given.

However, across this range of acceptable and unacceptable answers ran a common expectation among the patients, namely that of a particular kind of responsible receiver. The patients' primary concern was whether or not there would be one permanent contact person 'at the other end' of P-Record who would take their entire medical situation into consideration and be obliged to follow up and make things happen, which also links to the inherently easier task of addressing a specific or even well-known receiver. As Louis says:

There has to be more consistency: that the doctor who is to use this system also is the one following you over the course of several years. Because being a heart patient is not like having a disease that stops right now. I won't be cured tomorrow and that part of the heart that doesn't function will never function again. (Final interview with Louis)

In short, without an explicitly responsive and responsible receiver at the other end it would simply not be meaningful to make the extra effort of using P-Record. On this measure, the system failed in most cases. First of all, it only seemed to reproduce the lack of coherency often associated with distributed care as it still left it up to the patients to try to bridge institutional gaps and address the appropriate receiver. And secondly, P-Record delegated greater responsibility to patients for keeping track of their condition and treatment without a clear (interactive) goal. The importance of writing to someone and receiving a response simply meant that patients did not support the assumption that users would write for their own sake-an assumption expressed by some clinicians and part of the design script, especially the logbook function. Even here, the patients wrote with a receiver in mind and with the expectation that the clinicians would at least attend to the contents. As Ben put it:

[When writing in the logbook] I had in mind that the hospital would see it, keep an eye on it. Or when I am called in [for consultation], then they would just have a look. Now afterwards I don't know how much they actually looked at it. The doctor I saw he was not interested in anything. So if you were to [implement it] then I would hope that they have a look and read it, just like your medical record. (Final interview with Ben)

By insisting on an interactive use practice, Ben and the other patients can be said to resist central presumptions and ideals in the self-care discourse that guides many e-health designs, including P-Record.

\section{Concluding Discussion}

In the analysis, I have showed how patients sought to fulfil their roles as information 
providers by conducting dialogic assessments of relevance. They shaped their entries as contributions to a dialogue in the anticipation of response. Although this dialogic filtration work performed by patients, to some extent, made the system work as a filter, it also posed crucial challenges and paradoxically carried the seeds of the system's failure.

First, dialogic filtration work was not an easy task: shaping one's entries required certain skills and knowledge. The patients' entries must themselves be understood as responses-as continuations of a dialogue opened by the system. However, it was unclear who the 'sender' of the system was and thus the interlocutor one was in dialogue with. Patients solely had to draw on their experience with and knowledge about the infrastructure of care. Despite this being an explicit design ambition, the system in itself did not 'support patients' invisible work of bridging inter-institutional care" (Andersen et al., 2011b).

Second, undertaking dialogic filtration work entailed expectations of response. However, a vast difference between patients' and clinicians' perceptions of what constituted a satisfactory response became evident. The cardiologists, in particular, acted more as passive receivers than "implied responders" - the role that the patients "casted them in" (Linell, 2001: 104). The patients could, by and large, be said to experience the clinicians' responsive attitudes as either resulting in a discontinuation of the dialogue or, in a single case, leading the dialogue in an unwanted direction. In either case, this ultimately made using the system pointless to the patients.

The differences in expectations and attitudes between patients and clinicians link back to their differing descriptions of P-Record as a filtration device. For clinicians, P-Record showed potential as a tool for managing a dialogue, with filtration of information serving this purpose. In contrast, patients seemed to perceive P-Record as opening a dialoguewhether this presented as either a hopeful expectation or a negative anticipation. This difference might be conceptualized as an overall difference in communicative projects (Linell, 2001: 224) between patients and clinicians-or, in the terminology of Garfinkel (1967: 205), as different "interpretation schemes". Designing and implementing e-health requires careful considerations about which communicative projects a certain system is to support and an awareness of potential conflict between these projects. In the case of P-Record, while the system performed fairly well as a filtration device allowing clinicians to manage the dialogue, for most patients it did not perform well as a means to reach a responsive and responsible receiver. From a design-oriented perspective, the case thereby points to a crucial need for unfolding, negotiating and adjusting communicative projects of various users. Importantly, communicative projects are not stabile, but shaped by their mediators (the filtration devices) just as they also shape the use of these. As dynamic sociotechnical assemblages, users' experiences, communicative projects, and devices together make up the dynamic filters of e-health-dynamic, since the 'filter' is constantly adjusted "in the repeated iteration between (the filter) and the world, the expectation being revised each time" (Maurer, 2013: 66). When designing filtration devices, a central challenge therefore lies in how to support this continuous adjustment of expectations.

While unfolding, negotiating and adjusting communicative projects of users of e-health is by no means an easy feat, I suggest that a recognition of and engagement with the dialogical properties 
of the filtration work involved in the use of e-health is at least a place to start. I propose that an 'analytical filtration device' combining dialogism and studies of invisible work can generate insights into the participatory role as information providers that patients are given with e-health and into the implications it has for both patients and professionals and, ultimately, for the organization of healthcare. Often framed as levellers of participation, e-health technologies-and other participatory devices (Marres, 2012) - both entail and partly conceal substantial work by its users, as has also been pointed out by other studies. I suggest that filtration work is an important, but until now unrecognized, part of this invisible work of patient participation, and that inquiring deeper into what it means to be a participant can be done by unfolding its dialogic workings and implications. While dialogic filtration work is also part of faceto-face clinical encounters, the introduction of e-health seems to have the potential to complicate rather than to support this work, at least from a patient perspective, partly as processes of adjusting the filter-and the dialogue-are inhibited and/or concealed. This stresses the importance of also looking into how filtration work closely relates to the materiality of specific filtration deviceswithout ever being fully determined by it. In the case of P-Record, a rather ambiguous script meant that especially patients were poorly supported in their filtration work, with Ben as vivid example. Yet, a clearer script might have posed other challenges. Relations and practices of filtration (note the verb form) are the key here: if we think of filtration devices as 'filters in themselves' we overlook or even mask the skills, knowledge, and motivations that go into and result from making them work. Furthermore, looking at filtration illuminates how filters (as socio-technical practices) are not just transformative, but also generative: they create overflows, for instance (unmet) expectations. This seems inevitable, and when invoking 'filtration work' as an analytical tool in relation to e-health, it is important to not just treat the differing communicative projects and expectations resulting from and guiding the use of filtration devices as barriers to overcome in and by design. Rather, they point to and should be addressed through broader discussions about how modern healthcare can accommodate (itself to) patient participation, with all the work and overflows it implies. I suggest that STS-scholars may contribute to such discussions by experimenting with and, thereby, learning about what 'good filtration' between patients and clinicians might entail. Moreover, and as a conceptual and methodological addition to CSCWstudies of information work (e.g. Health \& Luff, 1996; Berg \& Goorman, 1999), 'experimenting with filtration' may also bring forth new insights in other contextsin healthcare and beyond-where the production and sharing of information undergoes (digital) formalization.

\section{Acknowledgements}

The author would like to thank the patients and clinicians who took part in this study. She owes great thanks to Henriette Langstrup for discussions and comments throughout the writing process and Jeannette Pols for inspiration and feedback on early drafts. Furthermore, she is grateful for the very helpful comments and suggestions provided by the two anonymous reviewers. 


\section{References}

Akrich M (1992) The De-Scription of Technical Objects. In: Bijker WE \& Law J (eds) Shaping Technology / Building Society. Cambridge, MA: The MIT Press, 205-224.

Andersen T, Bansler J, Kensing F, Moll J \& Nielsen KD (2014) Alignment of Concerns: A Design Rationale for Patient Participation in eHealth. In: 2014 47th Hawaiian International Conference on System Sciences (HICSS), Waikoloa, HI, USA, 6-9 January 2014: 2587-2596. IEEE.

Andersen T, Bjørn P, Kensing F \& Moll J (2011a) Designing for Collaborative Interpretation in Telemonitoring: Reintroducing Patients as Diagnostic Agents. International Journal of Medical Informatics 80(8): 112-126.

Andersen T, Halse J \& Moll J (2011b) Design Interventions as Multiple Becomings of Healthcare. In: Nordes '11: the 4th Nordic Design Research Conference - Making Design Matter, Helsinki, Finland, 29-31 May 2011: 11-20. Nordes.

Andersen T, Kensing F \& Moll J (2010) Designing IT and Healthcare - Patients as Co-producers. Paper abstract for the 2010 ACM Conference on Computer Supported Cooperative Work, Savannah, GA, USA, 6-10 February 2010.

Archer N, Fevrier-Thomas U, Lokker C, McKibbon KA \& Straus SE (2011) Personal Health Records: a Scoping Review. Journal of the American Medical Association 18(4): 515-522.

Bakhtin MM (1981) The Dialogic Imagination: Four Essays. Austin, TX: University of Texas Press.

Bakhtin MM (1986) Speech Genre and Other Late Essays. Austin, TX: University of Texas Press.
Basch E, Artz D, Dulko D, Scher K, Sabbatini P, Hensley M, Mitra N, Speakman J, McCabe M \& Schrag D (2005) Patient Online Self-Reporting of Toxicity Symptoms During Chemotherapy. Journal of Clinical Oncology 23(15): 3552-3561.

Berg M (1997) Rationalizing Medical Work: Decision-Support Techniques and Medical Practices. Cambridge, MA: The MIT Press.

Berg M (2002) Patients and Professionals in the Information Society: What Might Keep Us Awake in 2013. International Journal of Medical Informatics 66(1-3): 31-37.

Berg M \& Goorman E (1999) The Contextual Nature of Medical Information. International Journal of Medical Informatics 56(1-3): 51-60.

Berner ES \& Moss J (2005) Informatics Challenges for the Impending Patient Information Explosion. Journal of the American Medical Informatics Association 12(6): 614-617.

Borup M, Brown N, Konrad K \& van Lente $\mathrm{H}$ (2006) The Sociology of Expectations in Science and Technology. Technology Analysis \& Strategic Management 18(34): 285-298.

Brown N \& Michael M (2003) A Sociology of Expectations: Retrospecting Prospects and Prospecting Retrospects. Technology Analysis \& Strategic Management 15(1): 3-18.

Danholt P, Piras EM, Storni C \& Zanutto A (2013) Guest Editorial. The Shaping of Patient 2.0: Exploring Agencies, Technologies and Discourses in New Healthcare Practices. Science \& Technology Studies 26(2): 3-13.

Eysenbach G (2008) Medicine 2.0: Social Networking, Collaboration, Participation, Apomediation, and Openness. Journal of Medical Internet Research 10(3): e22. 
Felt U, Gugglberger L \& Mager A (2009) Shaping the Future E-Patient: the Citizen-Patient in Public Discourse on E-Health. Science Studies 22(1): 24-43.

Garfinkel H (1967) Studies in Ethnomethodology. Englewood Cliffs: Prentice-Hall, Inc.

Hanani URI, Shapira B \& Shoval P (2001) Information Filtering: Overview of Issues, Research and Systems. User Modeling and User-Adapted Interaction 11(3): 203259.

Hasu M \& Miettinen R (2006) Dialogue and Intervention in Science and Technology Studies: Whose Point of View? Working Papers 35, Center for Activity Theory and Developmental Work Research, University of Helsinki.

Heath C, Knoblauch H \& Luff P (2000) Technology and Social Interaction: the Emergence of "Workplace Studies". The British Journal of Sociology 51(2): 299320.

Heath C \& Luff P (1996) Documents and Professional Practice:"Bad" Organisational Reasons for "Good" Clinical Records. In: Proceedings of the 1996 ACM Conference on Computer Supported Cooperative Work (eds Olson GM, Olson JS \& Ackerman MS), Boston, MA, USA, 16-20 November 1996: 354363.

Jerak-Zuiderent S (2012) Certain Uncertainties: Modes of Patient Safety in Healthcare. Social Studies of Science 42(5): 732-752.

Kockelman P (2013) The Anthropology of an Equation. Sieves, Spam Filters, Agentive Algorithms, and Ontologies of Transformation. HAU: Journal of Ethnographic Theory 3(3): 33-61.

Langstrup H (2008) Making Connections Through Online Asthma Monitoring. Chronic Illness 4(2): 118-126.
Langstrup H, Iversen LB \& Vind S (2013) The Virtual Clinical Encounter: Emplacing Patient 2.0 in Emerging Care Infrastructures. Science \& Technology Studies 26(2): 44-60.

Leaver T, Willson M \& Balnaves M (2012) Transparency and the Ubiquity of Information Filtration. Ctrl-Z: New Media Philosophy 1(2).

Lehoux P, Sicotte C, Denis JL, Berg M \& Lacroix A (2002) The Theory of Use Behind Telemedicine: How Compatible with Physicians' Clinical Routines?. Sociology of Science \& Medicine 54(6): 889-904.

Linell P (2001) Approaching Dialogue: Talk, Interaction and Contexts in Dialogical Perspectives. Amsterdam: John Benjamins Publishing.

Marres N (2012) Material Participation. Technology, the Environment and Everyday Publics. London: Palgrave Macmillan.

Maurer B (2013) Transacting Ontologies: Kockelman's Sieves and a Bayesian Anthropology. HAU: Journal of Ethnographic Theory 3(3): 63-75.

May C, Rapley T, Moreira T, Finch T \& Heaven B (2006) Technogovernance: Evidence, Subjectivity, and the Clinical Encounter in Primary Care Medicine. Sociology of Science \& Medicine 62(4): 1022-1030.

Miller EA (2007) Solving the Disjuncture Between Research and Practice: Telehealth Trends in the 21st Century. Health Policy 82(2): 133-141.

Miller JG (1962) Information Input Overload. In: Yovits MC, Jacobi GT \& Goldstein GD (eds) Self-Organizing Systems. Washington, DC: Spartan Books, 61-78.

Moreira T (2011) Health Care Standards and the Politics of Singularities: Shifting In and Out of Context. Science, Technology \& Human Values 37(4): 307-331. 
Moreno-Ramirez D, Ferrandiz L, Bernal AP, Duran RC, Martín JJR \& Camacho F (2005) Teledermatology as a Filtering System in Pigmented Lesion Clinics. Journal of Telemedicine and Telecare 11(6): 298-303.

Mort M, May CR \& Williams T (2003) Remote Doctors and Absent Patients: Acting at a Distance in Telemedicine? Science, Technology, \& Human Values 28(2): 274-295.

Nicolini D (2006) The Work to Make Telemedicine Work: a Social and Articulative view. Social Science \& Medicine 62(11): 2754-2767.

Oudshoorn N (2008) Diagnosis at a Distance: the Invisible Work of Patients and Healthcare Professionals in Cardiac Telemonitoring Technology. Sociology of Health and Illness 30(2): 272-288.

Oudshoorn N (2011) Telecare Technologies and the Transformation of Healthcare. Basingstoke: Palgrave Macmillan.

Phillips L (2011) The Promise of Dialogue: The Dialogic Turn in the Production and Communication of Knowledge. Amsterdam: John Benjamins Publishing.

Piras EM \& Zanutto A (2010) Prescriptions, $\mathrm{X}$-rays and Grocery Lists. Designing a Personal Health Record to Support (the Invisible Work of) Health Information Management in the Household. Computer Supported Cooperative Work 19(6): 585-613.

Pols J (2012) Care at a Distance: on the Closeness of Technology. Amsterdam: Amsterdam University Press.

Pols J \& Willems D (2011) Innovation and Evaluation: Taming and Unleashing Telecare Technology. Sociology of Health \& Illness 33(3): 484-498.

Roberts C, Mort M \& Milligan C (2012) Calling for Care: "Disembodied" Work, Teleoperators and Older People Living at Home. Sociology 46(3): 490-506.
Savolainen R (2007) Filtering and Withdrawing: Strategies for Coping with Information Overload in Everyday Contexts. Journal of Information Science 33(5): 611-621.

Sinha AM, Koos R, Markus KU, Diem BH, Urbaszek A, Hanrath P \& Stellbrink C (2006) Multicentre Evaluation of a RuleBased Data Filter for Home Monitoring of Implanted Cardioverter Defibrillators. Journal of Telemedicine and Telecare 12(2): 97-102.

Star SL \& Strauss A (1999) Layers of Silence, Arenas of Voice: the Ecology of Visible and Invisible Work. Computer Supported Cooperative Work 8(1-2): 9-30.

Storni C \& Bannon LJ (2012) Towards the Design of Truly Patient-Centred Healthcare Infrastructures: a SocioTechnical Approach to Self-Care. In Chilamkurti N (ed) Health Informatics: an Adaptive Communication Technology for Future Healthcare. New York: Nova Science Publisher.

Suchman L (1995) Making Work Visible. Communications of the ACM 38(9): 5664.

Tenforde M, Jain A \& Hickner J (2011) The Value of Personal Health Records for Chronic Disease Management: What Do We Know? Family Medicine 43(5): 351354.

Wagner PJ, Howard SM, Bentley DR, Seol YH \& Sodomka P (2010) Incorporating Patient Perspectives into the Personal Health Record: Implications for Care and Caring. Perspectives of Health Information Management 7: 1e.

Warren S, Craft RL \& Bosma JT (1999) Designing Smart Health Care Technology into the Home of the Future. Workshops on Future Medical Devices: Home Care Technologies for the 21st Century, Rockville, MD, USA. 
Zuiderent-Jerak T \& Jensen CB (2007) Editorial Introduction: Unpacking "Intervention" in Science and Technology Studies. Science as Culture 16(3): 227-235.

\section{Notes}

1 I use the term e-health to denote various patient-involving information and communication technologies.

2 P-Record was designed through a collaborative research project, CITH - Co-constructing IT and Healtcare (www.cith.dk). The project resulted in a prototype that was then technically implemented by a software company. The name 'P-Record' is constructed for the purpose of this article as a common denominator for the prototypes and the implemented system. Although this conceals important differences between the various iterations, these are not the subject of analysis here and a common denominator is chosen to avoid unnecessary confusion.

3 Contrary to the often noted performative role of expectations in innovation processes (Borup et al., 2006), the case of P-Record is a story of the simultanous fuelling and 'failure of expectations' (Brown \& Michael, 2003).
4 The term 'filter' relates closely to such terms as 'sorting, 'sieving,' 'retrieving' and 'selecting.' I use the term 'filter' because it is already commonly used in relation to information and communication technology and thus constitutes a 'native' metaphor. I use both the noun and verb form in order to capture the tension between perceived automatized 'filters' and the practices involved in making them function as such.

5 In the logbook patients could write free text categorized as either diary, note of symptoms, or illness history. This part of the system was not explicitly associated with upcoming appointments but the entries would, nonetheless, be visible to clinicians.

6 In the medication list feature, patients could create an overview of their medication and enter information about doses, side effects, and date of prescription.

Karen Dam Nielsen, PhD, Postdoc

Section for Human-Centred Computing

Department of Computer Science,

University of Copenhagen

Njalsgade 128-132, DK-2300 Copenhagen S,

Denmark

kani@di.ku.dk 